DOI: 10.12731/2077-1770-2021-13-3-236-262

УДК 811.112.2'42:004.738.5

\title{
ПРОТЕСТНАЯ МОБИЛИЗАЦИЯ \\ В СООБЩЕСТВАХ СОЦИАЛЬНЫХ СЕТЕЙ ГЕРМАНИИ: ПРОСТРАНСТВЕННО-ВРЕМЕННОЕ ИЗМЕРЕНИЕ (ДИСКУРСИВНАЯ И ЖАНРОВАЯ СПЕЦИФИКА)
}

\section{Генералова Л.М.}

Цель. В статье изложень результаты анализа пространственно-временного измерения конфликтной мобилизации как современной практики протестной коммуникации всообществах социальных сетей. Дана характеристика интерактивному инструментарию сообществ конфликтной мобилизачии и взаимосвязи межсу различныли вероятныли параметрами сообществ. Описано дискурсивное пространство сообществ конфликтной мобилизачии, делается вывод о преобладании событийно-ориентированной манеры общения; асихронности жанра; самореферентности сощиальных сетей; классификации сообществ по авторскому составу, исходя из мультимедийной составляющей, тематике содержания, общих показателях сочиильных сетей, таких как выражение собственной позиции по декларируемому событию, фактичность, аргументированность, интенциональность.

Метод или методология проведения работы. Эмпирический материал был отобран методом сплошной выборки на официальных платформах сочиальных сетей. Методы исследования включают в себя общенаучные методы анализа и синтеза, интерпретативный метод, контент-анализ, стилистический метод, применяемый для анализа фрагментов сообществ конфликтной мобилизации.

Результаты. Рассмотрены жанровые параметры конфликтной мобилизачии в сочииальных сетях, детерминирована корреляичия между предметом выступления и толкованием изложенных фактов, описана двухуровневая система построения соииальных сетей и характер ее публикационного содержания. Показывается, 
что дискурсивное многообразие платформы сочиальных сетей обусловлено сложностью внутренних коммуникационных процессов, а также многочисленными дискурсивными признаками соцсетей как продукта интернет-коммуникации.

Область применения результатов. Результаты исследования могут быть использованы в базовом курсе прикладной лингвистики, лингвокультурологии и социолингвистике.

Ключевые слова: протестная коммуникация; конфликтная мобилизачия,пространственно-временные измерения; конфликтная мобилизация; сообщество в сочиальной сети; жанровая и дискурсивная гибридность

\section{PROTEST MOBILIZATION IN GERMAN SOCIAL NETWORK COMMUNITIES: SPATIO-TEMPORAL DIMESNSION (DISCURSIVE AND GENRE CHARACTERISTICS)}

\section{Generalova L.M.}

Purpose. The present article sets out the results of the analysis of the spatio-temporal dimension of conflict mobilization as a modern practice of protest communication in social network communities. The article considers the interactive tools of conflict mobilization communities; the relationship between the various likely parameters of the communities. The article describes the discursive space of communities of conflict mobilization, concludes about the predominance of event-oriented manner of communication; the asychronicity of the genre; the self-reference of social networks; the classification of communities by the author's composition, based on the multimedia component, the subject of the content, the general indicators of social networks, such as the expression of one's own position on the declared event, facticity, argumentativeness, intentionality.

Method or methodology of the study. The study was conducted with the method of overall selection of empirical material from the official social networks platforms. Research methods include general scientific methods of 
analysis and synthesis, an interpretive method, content analysis, a stylistic method used to analyse fragments of communities of conflict mobilization.

Results. Genre parameters of conflict mobilization in the social networksare considered, the correlation between the subject of the speech and the interpretation of the stated facts is defined, both the two-level system of building social networks and the nature of its publication content are described. It is revealed that the discursive diversity of the social network platform relates to the complexity of internal communication processes, as well as numerous discursive features of social networks as a product of Internet communication.

Practical implications. The research results can be used in the basic course of applied linguistics, linguoculturology and sociolinguistics.

Keywords: protest communication; conflict mobilization; spatio-temporal measurements; conflict mobilization; social network community; genre and discursive hybridity

\section{1. Реализация конфликтной мобилизации в сообществах социальных сетей в практике протестной коммуникации}

Вследствие быстрого формирования информационных технологий Интернет преобразовался за минувшие десятилетия в сильную платформу для выражения общественного мнения, а кроме того, стал средством коммуникации представителей протестного движения. В результате этих трансформаций произошло перераспределение его общественно-коммуникативных функций и способностей. Интернет рассматривается сегодня как техническая инфраструктура, основанная на ценности свободы и возможности участия и выражения мнения каждого человека.

Новые коммуникационные технологии позволяют манипулировать, провоцировать индивида и общество благодаря процессу мобилизации (вовлечения) определенного круга лиц в различные формы политической активности, что особенно ярко проявляется в социальных сетях, где виртуальная реальность замещает одну из самых важных сфер человеческой жизни - сферу межличностного общения, дружбы, симпатий, увлечений.

Во множестве индивидуальных и коллективных повествований на платформах социальных сетей раскрывается не только сущность про- 
теста, но и индивидуальность протестующего. Под мобилизацией мы будем понимать ряд мер, направленных на активизацию гражданской активности относительно участия в социально-значимом событии или принятии решений через убеждение, награждение, принуждение [17]. Центральное место в процессе мобилизации занимает фундаментальное понимание коллективных идей и потребностей. Важно мотивировать заинтересованные группы, отстаивать свои цели и реализовывать идеи с помощью мобилизации всех доступных ресурсов.

Популярность социальных сетей (СС) в современном медиапространстве объясняется различными типами цифровой сетевой коммуникации (сетевые платформы, видеоплатформы, веб-журналы), которые с разной степенью интенсивности позволяют каждому демонстрировать свои креативные способности без каких-либо ресурсных ограничений, неограниченными возможностями визуализации контента, доступностью подаваемой информации [13].

Рассматривая феномен мобилизации, ученые различают конфликтную и позитивную мобилизации [9], а также дифференцируют определенные типы коллективных действий при мобилизации, которые «встроены» в социальные сети [19]. Все это призвано обеспечить организационную основу для возникновения новой динамики мобилизации, изменить процесс формирования идентичности, публичности и прозрачности предоставляемой информации. Протестная мобилизация обнаруживает следующие этапы, играющие важную роль при интернет-коммуникации: а) информирование граждан посредством сообщений, идей, мемов; б) этап «кластеризации» - поиск и объединение людей с подобными интересами, мнениями и коллективным мышлением; в) призыв к коллективным действиям, согласованные активные формы поведения; г) обсуждение проведенной онлайн-акции [11]. Процесс мобилизации может быть реализован при помощи внутреннего (личные убеждения и мотивы адресата) или внешнего (влияние окружения или других экзогенных факторов) механизмов [21].

Рассматривая механизм мобилизации в социальных сетях, следует отметить следующее: 
- все субъекты коммуникации находятся во взаимозависимых отношениях друг с другом;

- субъекты связаны определенными социальными отношениями, благодаря которым передается информация;

- структура этих отношений ограничивает или допускает социальную активность;

- отношения между собеседниками определяются индивидуальными, экономическими, политическими и др. ориентациями и интересами.

Только в этом случае информация воспринимается как достоверная (релевантная).

Помимо адресанта коммуникации, сообщества социальных сетей включают также адресатов (потребителей) новостного контента. К ним относятся активные интернет-пользователи, умеренно активные интернет-пользователи, интернет-скептики [8].

Основными способами привлечения гражданских лиц к мобилизации являются информационные (предоставление информации, разной по содержанию), организационные (создание условий для объединения в группу единомышленников), семантические (влияние на сознание индивида при помощи культурно значимых ценностей и норм), психологические (управление эмоциональным фоном посредством мотивации, манипуляции), коммуникативные (обсуждение социально-значимых проблем), педагогические (развитие мышления, расширение кругозора, повышение образования) [11].

Успешная мобилизация обусловлена и определенными структурными условиями, такими как пространственная концентрация (шансов на мобилизацию больше у жителей крупных мегаполисов, чем упроживающих в удаленных населенных пунктов), однородность социальной группы.

В качестве удачных мобилизационных технологий ученые выделяют идею (ценности и идеалы, сплачивающие людей в группы), наличие лидера (личность, которая мобилизует людей к действиям ради идеи), инициативная группа (приближенный к лидеру круг лиц, которые являются связующим звеном между ним и остальным адресатом), проект (программа с намеченной деятельностью), обязатель- 
ное освещение проекта в медиа с целью привлечения общественного внимания, реализация проекта в жизнь, обсуждение проекта (оценка результатов и дальнейшего развития) [14].

Не менее значимыми условиями положительной мобилизации являются ссылки на внешние ресурсы, активные связи с другими сообществами, регулярность публикаций, апелляции к авторитетным экспертам [15].

\section{2. Методология исследования пространственно-временного} измерения протестной мобилизации всообществах СС

Предметом исследования являются пространственно-временное измерение протеста в немецкоязычных сообществах СС, рассматриваемое нами с позиции современного системно-коммуникативного подхода, т.к. полная интерпретация современного протеста предписывает системный анализа, включающий в себя пространственно-временные (специфические хронотопические особенности и характерные признаки); предметные (социальные мотивы, дистинкция, проактивное - реактивное, решение - поражение: тему протеста, послужившую стимулом участников к действию, логическое проектирование ситуации / проблемы) и коллективно-личностные (характеристики участников протестных практик; уровни их взаимодействия; коммуникативные стратегии и тактики) изменения [3;5].

Предмет исследования - пространственно-временное измерение как элемент системно-коммуникативных характеристик немецкоязычных практик конфликтной мобилизации всообществах СС, который посредством процессов категоризации, наименования, индексации создает и передает общие знания о протестных практиках какконструктивном элементе медиатизации протеста.

Материал исследования - публикации, соответствующие следующим критериям: а) публикация размещена в СС Германии (например: Facebook, Twitter, Wer-kennt-wen.de, Yooco.de, Lokalisten.de); б) публикация относится к медиаконтенту сообщества, созданного для решения определенной проблемы(например, сообщества в социальных сетях Facebook, Twitter: «Bündnis gegen Rechts Magdeburg» 
[BGRM], «Deutsche Umwelthilfe» [DU], «Fridays gegen Altersarmut» [FGA] и др.); в) публикация связана с определенными событиями, которые вызвали протестные выступления онлайн или офлайн; г) период публикации: 2014-2021 гг. Каждое сообщение сопровождают следующие рубрики: 1) тема (общественная, экологическая, политическая и т.д.); 2) высказывание собственного мнения адресанта (отдельного индивида или группы лиц) по данной проблеме; 3) аргументирование (видео, фото, статистические данные; 4) комментарии аудитории. Объем выборки составил около 1000 публикаций с различной тематикой, адресацией и статусом.

Стратегическое действие конфликтной мобилизации всообществах СС соотносится смногогранной теорией коммуникативных действий Ю. Хабермаса, где действующими лицами выступают говорящие и слушающие субъекты, которые связаны определенными отношениями с «объективным, социальным или субъективным миром», выдвигая одновременно определенную точку зрения на то, о чем они говорят, думают, в чем они убеждены [8; 4].

В статье предусмотрены следующие исследовательские задачи: описание интерактивного функционала; изучение дескриптивной статистики сообществ СС; описание способов экспликации мобилизационного эффекта адресантом втекстах публикаций; выявление жанровой и дискурсивной специфики сообществ социальных сетей, исходя из совокупности коммуникативных, прагматических и языковых признаков; установлениепревалирующихвидов жанра в данных сообществах.

\section{3. Пространственно-временное измерение (дискурсивная, жанровая специфика) \\ 3.1. Метаданные сообществ}

\section{и характеристика их участников}

Анализируемые нами сообщества имеют общий функционал: информация о группе (включает в себя название группы, статус, историю создания, тип, администраторов и модераторов, правила группы от администраторов, данные об участниках группы, показатели о публикациях и изменениях в группе); вкладка «Обсуждение» 
(комментирование и виртуальность публикаций участниками группы); вкладка «Участники» (содержит информацию об администраторах, модераторах и участниках группы); вкладка «Еще» (включает темы, мероприятия группы, файлы и медиафайлы); функция «вступить в группу», отправив соответствующий запрос; функция поиска публикаций или участников; возможность поделиться информацией о группе или пожаловаться на нее. На многих платформах социальных сетей незарегистрированные пользователи имеют ограниченную возможность просмотра демонстрационной версии сети. После регистрации пользователь получает доступ к функции поиска и комментирования. Проведенный нами анализ показал, что закрытые сообщества СС имеет меньшее количество участников, чем общедоступные; сообщества смалым количеством участников имеют также небольшой состав администраторов; динамика размещения нового контента не обусловлена типом сообщества и количеством его членов.

Статистика размещения контента в исследуемых сообществах СС

\begin{tabular}{|c|c|c|c|c|c|}
\hline Название группы & $\begin{array}{c}\text { Тип группы } \\
\text { (общедоступ- } \\
\text { ная/ закрытая } \\
\text { - О/ 3) }\end{array}$ & $\begin{array}{c}\text { Дата } \\
\text { созда- } \\
\text { ния }\end{array}$ & $\begin{array}{l}\text { Числен- } \\
\text { ность }\end{array}$ & $\begin{array}{c}\text { Количество } \\
\text { новых пу- } \\
\text { бликаций } \\
\text { за день }\end{array}$ & $\begin{array}{l}\text { Наличие ад- } \\
\text { министра- } \\
\text { тора/ моде- } \\
\text { ратора }\end{array}$ \\
\hline Deutsche Umwelthilfe & $\mathrm{O}$ & 21.11 .13 & 23393 & 2 & $\begin{array}{l}\mathrm{A}-1 \\
\mathrm{M}-1\end{array}$ \\
\hline $\begin{array}{l}\text { Fridays gegen } \\
\text { Altersarmut }\end{array}$ & $\mathrm{O}$ & 25.09 .19 & 283800 & 1 & $\begin{array}{l}\mathrm{A}-2 \\
\mathrm{M}-1\end{array}$ \\
\hline $\begin{array}{l}\text { Bündnis gegen } \\
\text { RechtsMagdeburg }\end{array}$ & $\mathrm{O}$ & 15.11.11 & 1592 & 0,8 & A-1 \\
\hline $\begin{array}{l}\text { Mensch und Politik } \\
\text { heute }\end{array}$ & $\mathrm{O}$ & 13.10 .16 & 1700 & 13 & $\begin{array}{l}\text { A-5 } \\
\text { M-2 }\end{array}$ \\
\hline $\begin{array}{l}\text { Junge Union } \\
\text { Deutschlands }\end{array}$ & $\mathrm{O}$ & 04.02 .09 & 48310 & 1 & A-1 \\
\hline $\begin{array}{l}\text { Grüne Ökonomie: nach- } \\
\text { haltiges Wirtschaften } \\
\text { und erneuerbare En- } \\
\text { ergie }\end{array}$ & $\mathrm{O}$ & 21.12 .10 & 4395 & 10 & A -6 \\
\hline Seeheimer Kreis & $\mathrm{O}$ & 07.01 .09 & 6608 & 2 & A-1 \\
\hline $\begin{array}{l}\text { Eckhart Tolle } \\
\text { Deutschland }\end{array}$ & 3 & 25.04 .19 & 31400 & 24 & $\begin{array}{l}\text { A-2 } \\
\text { M-5 }\end{array}$ \\
\hline Alle Gegen Rechts & 3 & 24.01 .12 & 504 & 4 & A-5 \\
\hline $\begin{array}{l}\text { Gemeinsam gegen } \\
\text { Nazis }\end{array}$ & 3 & 16.02 .12 & 1200 & 0,6 & $\begin{array}{l}\text { A-5 } \\
\text { M-1 }\end{array}$ \\
\hline
\end{tabular}




\section{2. Дискурсивная характеристика сообществ конфликтной мобилизации в СС}

В данной статье под дискурсом мы будем понимать сложное коммуникативное явление, включающее в себя не только простое построение текста, но и когнитивную репрезентацию экстралингвистических факторов, необходимых для осмысления и понимания этого текста [7].

Это своего рода сотрудничество коммуникантов по поводу решения важных общественно-политических проблем с помощью вербальных и невербальных средств с привлечением в дискуссию разных общественных сил: индивидов, социальных групп, общественных организаций и политических движений $[18$, p. 11]. Это не просто интертекстуально связанные высказывания, которые соотносятся друг с другом, помогают понять отражаемое событие, объекты, ситуации, но являются практиками, которые создают и передают общепринятые знания при помощи процессов категоризации, номинации и индексации и представляют «новые возможности реализации ценностно-маркированных современным индивидом потребностей» [10, с. 84].

Говоря о дискурсивном пространстве социальных сетей, мы учитываем тот факт, что «дискурс, будучи динамическим процессом, отражающим функциональные особенности речи, имеет в то же время все черты её прагматических, экспрессивных и когнитивных свойств» [1, с. 337].

Дискурс СС как отдельный вид дискурса представляет собой комбинацию всевозможных текстов, оформленных не только разнообразными лингвистическими средствами, но также специфическими ресурсами невербального общения.

В отличие от других средств общения, где единицей информации является слово или текст, пользователь СС привлекают к себе внимание при помощи вербальных, визуальных и аудиовизуальных средств (аудио, видео, граффити, документы, статусы, логотипы, аватар и т.д.)

Для дискурса социальных сетей характерны такие свойства коммуникации, как: 
- динамичность (диалог пользователей как основа любой коммуникации);

- коммуникативность (обязательным условием является установка на общение и поиск собеседника);

- персонифицированность;

- ситуативная обусловленность (ситуативные особенности протекания коммуникации);

- коннотативность (особенности жаргона, использование дополнительных эмоциональных маркеров как, например, смайлики, мемы и т.д.) [12].

Для дискурса СС показательна событийно-ориентированная манера общения. Освещаемые события считаются актуальными и перспективными в плане продолжения только в том случае, если они становятся источником следующих публикаций и обсуждений.

За счет нелинейной подачи информации, наличию разноуровневых ссылок, постоянному обновлению данныхсоциальные сети становятся главной площадкой для дискурсивного обсуждения значимых общественно-политических событий и мобилизации протеста. Что, в свою очередь, лишает другие СМИ монополии на выражение общественного мнения.

Как показало наше исследование, классификация социальных сетей Германии основывается, как правило, на следующих признаках:

- по авторскому составу: личные, групповые или общественные;

- по тематике содержания: политические, спортивные, экономические, экологические и т.д.;

- исходя из мультимедийной составляющей: текстовые, комплексные (с аудио- или видеокомпонентами, граффити);

Платформы социальных сетей характеризуются также дискурсивной комбинированностью и визуализированностью вследствие сложности внутренних коммуникационных процессов, что можно объяснить многочисленными признаками социальных сетей как продуктаинтернет-пространства: 


\begin{tabular}{|c|c|c|c|}
\hline $\begin{array}{c}\text { Тип } \\
\text { дискурса }\end{array}$ & Признаки & Примеры & $\begin{array}{c}\text { Значимые средства } \\
\text { выражения }\end{array}$ \\
\hline $\begin{array}{l}\text { Информаци- } \\
\text { онный (25 \%) }\end{array}$ & $\begin{array}{l}\text { двусторонний } \\
\text { поток инфор- } \\
\text { мации, презен- } \\
\text { тационность, } \\
\text { регулятив- } \\
\text { ность, цели, } \\
\text { стратегии }\end{array}$ & 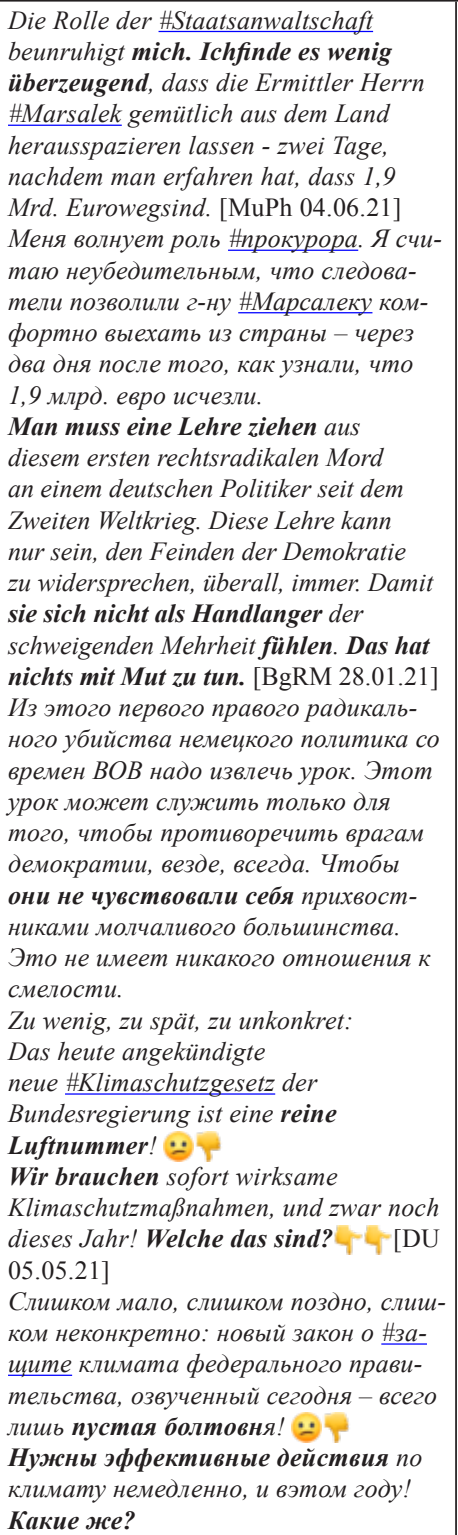 & $\begin{array}{l}\text { личные местоиме- } \\
\text { ния, лексика, назы- } \\
\text { вающая эмоции, пе- } \\
\text { реживания, лексиче- } \\
\text { ские единицы (ЛЕ) } \\
\text { с количественной } \\
\text { семантикой, оце- } \\
\text { ночной семантикой, } \\
\text { репрезентанты эти- } \\
\text { ческих концептов, } \\
\text { хрононимы, ЛЕ с } \\
\text { семантикой должен- } \\
\text { ствования, необходи- } \\
\text { мости, инклюзивные } \\
\text { местоимения, рито- } \\
\text { рический вопрос }\end{array}$ \\
\hline
\end{tabular}


Продолжение табл.

\begin{tabular}{|c|c|c|c|}
\hline $\begin{array}{l}\text { Политиче- } \\
\text { ский (15 \%) }\end{array}$ & $\begin{array}{l}\text { связь с раз- } \\
\text { личными об- } \\
\text { щественными } \\
\text { организациями } \\
\text { и движениями, } \\
\text { своеобразные } \\
\text { вербальные и } \\
\text { невербальные } \\
\text { символы, аги- } \\
\text { таторство и } \\
\text { пропагандизм, } \\
\text { актуальность, } \\
\text { персуазив- } \\
\text { ность, оценоч- } \\
\text { ность }\end{array}$ & 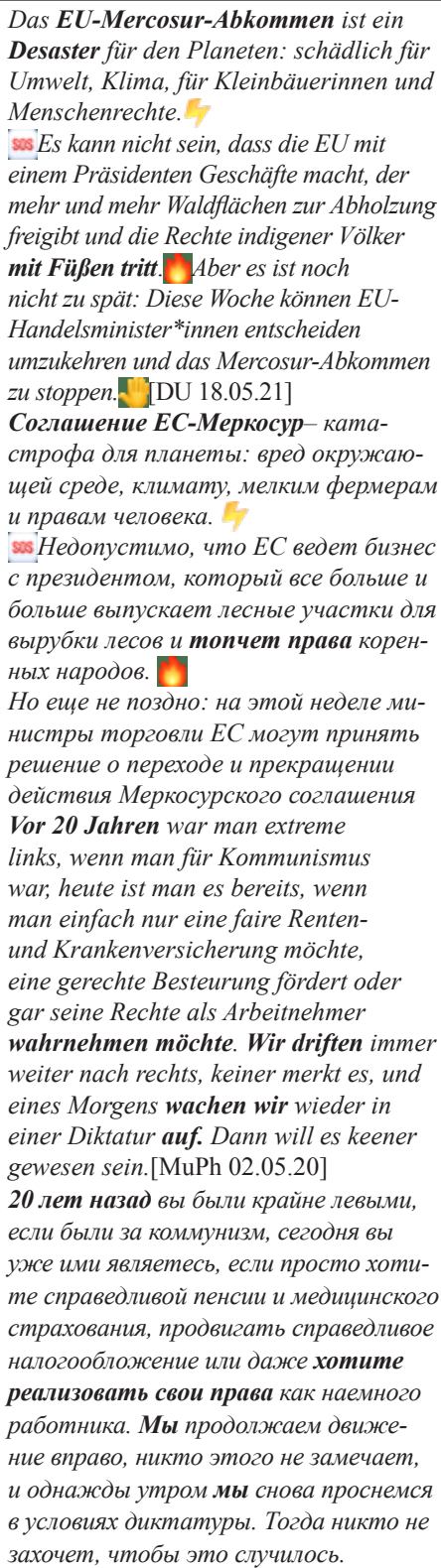 & $\begin{array}{l}\text { Имена собственные, } \\
\text { абстрактные ЛЕ, ЛЕ } \\
\text { с оценочной семан- } \\
\text { тикой, инклюзивные } \\
\text { местоимения, нео- } \\
\text { пределенные место- } \\
\text { имения, перформа- } \\
\text { тивные глаголы, хро- } \\
\text { нонимы }\end{array}$ \\
\hline
\end{tabular}


Окончание табл.

\begin{tabular}{|c|c|c|c|}
\hline $\begin{array}{l}\text { Публицисти- } \\
\text { ческий (15 \%) }\end{array}$ & $\begin{array}{l}\text { объективность, } \\
\text { фактологич- } \\
\text { ность, персуа- } \\
\text { зивность, оце- } \\
\text { ночность и экс- } \\
\text { прессивность, } \\
\text { выражение сво- } \\
\text { его отношения к } \\
\text { предмету речи }\end{array}$ & 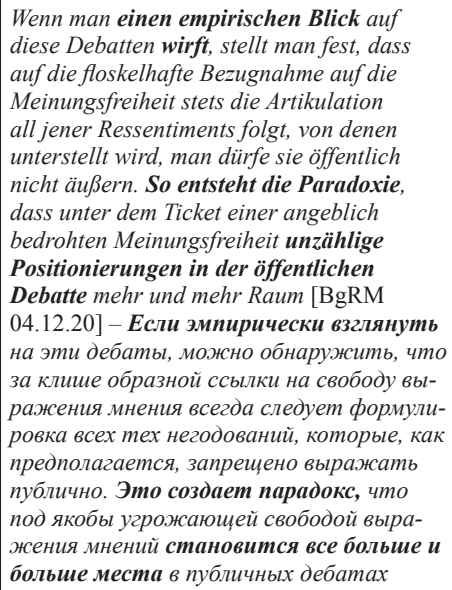 & $\begin{array}{l}\text { ЛЕ, которые экспли- } \\
\text { цируют логическую } \\
\text { связанность изложе- } \\
\text { ния мысли, пассивные } \\
\text { конструкции }\end{array}$ \\
\hline $\begin{array}{l}\text { социально-о- } \\
\text { риентирован- } \\
\text { ный (10\%) }\end{array}$ & $\begin{array}{l}\text { социально-зна- } \\
\text { чимая инфор- } \\
\text { мация, мотива- } \\
\text { ционность, оце- } \\
\text { ночность }\end{array}$ & 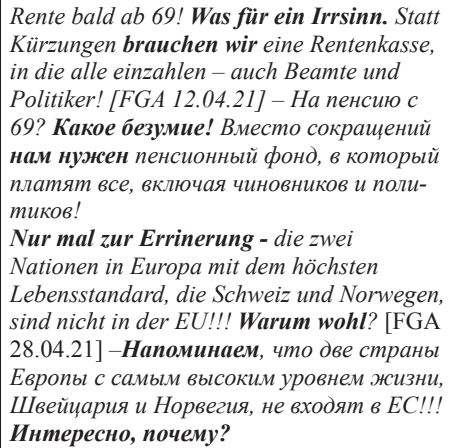 & $\begin{array}{l}\text { ЛЕ с эмоционально- } \\
\text { оценочной семанти- } \\
\text { кой, личные местои- } \\
\text { мения, перформатив- } \\
\text { ные высказывания, } \\
\text { риторические во- } \\
\text { просы }\end{array}$ \\
\hline $\begin{array}{l}\text { интернет-дис- } \\
\text { курс }(35 \%)\end{array}$ & $\begin{array}{l}\text { виртуальность, } \\
\text { дистантность, } \\
\text { неформальное } \\
\text { общение, жан- } \\
\text { ровое многооб- } \\
\text { разие, гетеро- } \\
\text { генность участ- } \\
\text { ников }\end{array}$ & 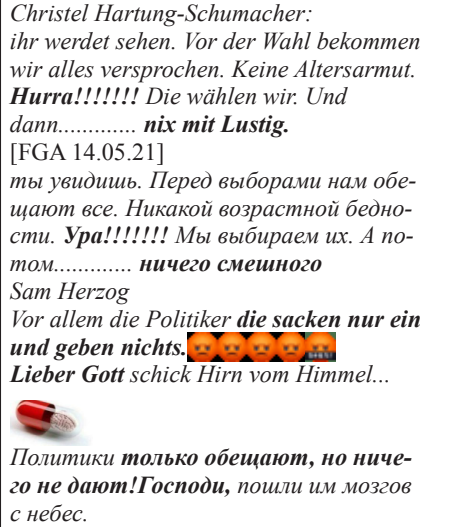 & $\begin{array}{l}\text { Разговорные и просто- } \\
\text { речные лексические } \\
\text { единицы, эмоциональ- } \\
\text { но-экспрессивные } \\
\text { ЛЕ, синтаксическая } \\
\text { неполнота, бессоюз- } \\
\text { ные предложения, } \\
\text { обилие эмотиконов и } \\
\text { стикеров. }\end{array}$ \\
\hline
\end{tabular}


Общими показателями социальных сетей Германии являются: выражение собственной позиции по декларируемому событию, фактичность, аргументированность, интенциональность, массовый адресат [5].

\section{3. Жанровые характеристики сообществ конфликтной мобилизации в СС}

В своем исследовании мы анализируем жанровые особенности сообществ конфликтной мобилизации в СС исходя из модели описания жанра, предложенной Л.Ю. Шипицыной, которая включает в себя «медийные» (в каком формате?), прагматические (кто? кому? зачем? где?), структурно-семантические (что?) и лингвостилистические параметры (как?) [16].

Интерфейс сообществ конфликтной мобилизации в СС своеобразно структурирован, что обусловленоправилами интернет-платформы, на которой они располагаются. Для публикации сообщения существуют следующие площадки: личная страница (индивидуальный открытый профиль пользователя) - составляет 25\% от всех проанализированных сообществ, публичная страница - представляет определенную организацию, бренд или тематику (открыт для всех, но публикации доступны только администраторам - 20\%), группа (возможность публикации детерминирована определенными правилами $-55 \%$ ). Сообщества социальных сетей обязательно объединены по интересам. Пользователь, который создал сообщество, является, как правило, его администратором. Чаще всего распространены сообщества, которые представлены коммерческими, некоммерческими, политическими, общественными организациями и созданы с целью реализации определенных задач, целей, программ. Публичные посты отличает гипертекстуальный характер, т.к. они содержат ссылки на другие тексты, в том числе из внешних источников, могут быть различной тематики (носить политический, познавательный, информационный или развлекательный характер), содержать текстовой или мультимедийный контент. Размещение информационных блоков в социальных сетях происходит регулярно, количество постов, разме- 
щенных за день, может варьироваться, всегда присутствует отметка о времени публикации сообщения. Непрерывное обновление подаваемой информации способствует эффективному коммуникативному обмену между читателями при помощи функции комментирования. Социальные сети активно развиваюткоммуникативные максимы, комбинируя и интегрируя когда-то отдельные континуумыдруг с другом.

Важным жанровым признаком сообществ конфликтной мобилизации вСС является их мультимедийность, которая выражается в «соединении вербального текста с невербальными компонентами - графикой, картинками, видео, анимацией» [2, с. 28]. Все сообщения размещаются под заголовками, с которыми связаны метки, фото, видео, рисунки и т.д. Данные материалы являются своего рода «визитной карточкой» сообщества, указывают на определенное тематическое содержание контентаипозволяют делать выводы об интересах и образе мышления участников группы.

В качестве подтверждения вышеизложенного приведем следующий пример: политическая организация «Bündnis gegen RechtsMagdeburg» разместила на своих страницах в социальных сетях Twitter.de и Facebook.com пост с призывом выйти на акцию протеста против марша нацистов в г. Магдебурге, снабдив заметку ярким баннером и видеоматериалом:

\section{MagdeburgNazifrei(@MD_Nazifrei)}

Bündnis zur verstärkten Mobilisierung zu den Gegenaktionen zum jährlichen Nazimarsch

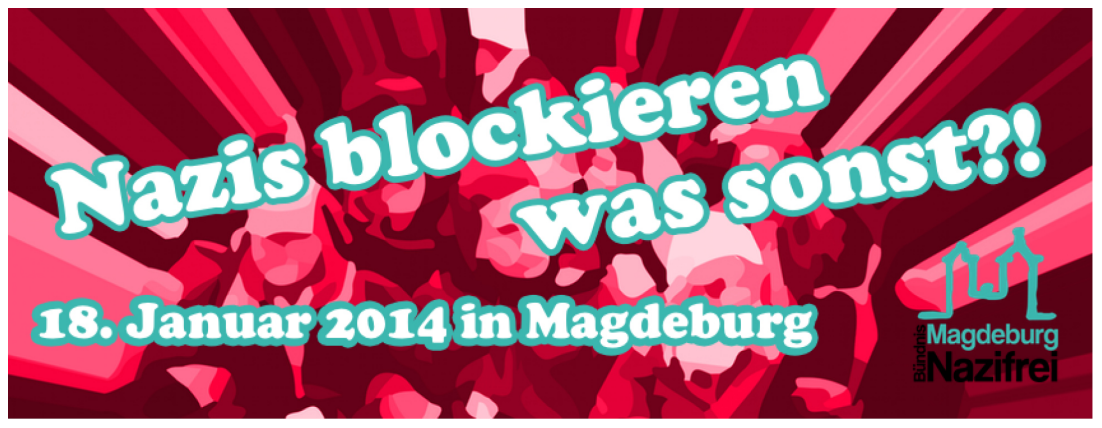

https://www.facebook.com/watch/live/?v=1780001932033944\&ref=watch_permalink 
Протест осуществляется мобилизующим образом, специфичным для СС, с размещением яркого баннера и общей формулировкой призыва к протесту:

„,̈̈berall in der Stadt sollen vielfältige und friedliche Aktionen stattfinden. [...] Lassen Sie uns den Nazis gewaltfrei mit Zivilcourage und Entschlossenheit entgegentreten! “

Имеется также четкое указание мест протеста, что свидетельствует об офлайн-мобилизации: «По всему городу должны проводиться разноплановые и мирнье акции. [...] Давайте противостоять нацистам ненасильственно, мужественно и решительно! "

\section{Прагматические параметры конфликтной мобилизации в СС}

Преимуществом общения в социальной сети является возможность членов сообщества коммуницировать друг с другом дистанционно, используя навигационные метки и информационные блоки, в чем заключается самореферентность социальных сетей. Основным мотивом модератора является потребность выразить себя экспертом в обсуждении значимой общественно-политической темы. Ранее мы указали на то, что каждое сообщество СС занимает определенную позицию и трактует происходящее, исходя из собственных целеустановок. Таким образом, социальная сеть позволяет выразить себя, найти сторонников и последователей. Для коммуникации в сети не всегда необходимо наличие обоих коммуникантов, каждый может в определенный момент оставить свой комментарий на стене. Это выступает маркером асихронности жанра социальных сетей.

Keine Zusammenarbeit mit der extremen Rechten! Diese Position soll morgen auf dem Domplatz, vor Landtag und Landesregierung sichtbar werden.

Dazu braucht es Menschen, die das deutlich machen - mit Anstand und Abstand. Um 16.00 Uhr geht es auf dem Domplatz. \#Magdeburg\#unteilbarlsa [BgRM] 21.04.21

Никакого сотрудничества с крайне правыми! Эту позиичю можно будет увидеть завтра на Домплаце, перед парламентом федеральной земли и ее правительством. 
Для этого нужны люди, которые дают понять это - соблюдая приличия и дистанщуию. В 16.00 часов на Соборной площзади.

Призыв к протестным выступлениям офлайн находит общественный резонанс среди читателей сообщества:

\section{Peter Kydcia}

ABSOLUT RICHTIG (Абсолютно правы)

\section{Josefa Lorencic}

\section{Richtig๖ (Правильно)}

\section{Leon Höchst}

gibt es eine gemeinsame Zuganreise aus Berlin? (Eсть ли совместный выезд из Берлина?)

Сообщение детерминировано концепцией модераторов, опубликованной ими информацией, в комментарии к заметке просматривается корреляция между предметом выступления и толкованием изложенных фактов.

Следующая заметка содержит выступление известного немецкого политика Сары Вагенкнехт по поводу недопустимости сокращения пенсионного возраста:

Rente bald ab 69? Was für ein Irrsinn. Statt Kürzungen brauchen wir eine Rentenkasse, in die alle einzahlen - auch Beamte und Politiker! [FgA] 12.04.21

На пенсию в 69? Какое безумие. Вместо сокращений нам нужен пенсионный фонд, в который платят все,включая чиновников и политиков!

Политиком представлена упорядоченная информация, в которой она критикует принятие правящей партией очередного закона, предлагает выход из сложившейся ситуации и прогнозирует дальнейший ход событий. Речь Вагенкнехт базируется на совокупности фактов и аргументов, основу которых составляет обращение к нравственным, человеческим ценностям.

Еще одним жанровым признаком социальных сетей являются структурно-семантические параметры, которые находят свое выражение в двухуровневом построении социальных сетей - «вертикальном» и горизонтальном» [16]. Для вертикального строения 
характерно анахроническое расположение записей, составляющих множество блоков: главная страница с информацией о сообществе, инструменты навигации, заголовки, подзаголовки, всевозможные теги и ссылки, фото, комментирование читателей.

Горизонтальное строение определяется публикационным содержанием сообщества, может быть монотематичным и политематичным.

\section{Стилистические и языковые параметры сообщества протестной коммуникации СС}

Выбор языковых средств на данных интернет-площадках обусловлен устно-письменной комбинированностью оформления этого жанра коммуникации. Для заголовков заметок чаще всего характерны эллипсы, короткие синтаксические или инфинитивные конструкции:

Keine Lust auf Hass und Hetze? Dann kommt auf den Domplatz! [BgRM]

Zum heutigen Internationalen Tag gegen \#Rassismus Erinnerung. Gerechtigkeit. Aufklärung. Konsequenzen [BgRM]

Antibiotikamissbrauch in der Massentierhaltung [DU]

9.2. Wenn die Politik nicht aktiv wird, müssen wir handeln: S[DU]

Реже в качестве заголовка выступает ссылка на событие или мероприятие:

http://deraufstand.wihuman.de/[FgA]

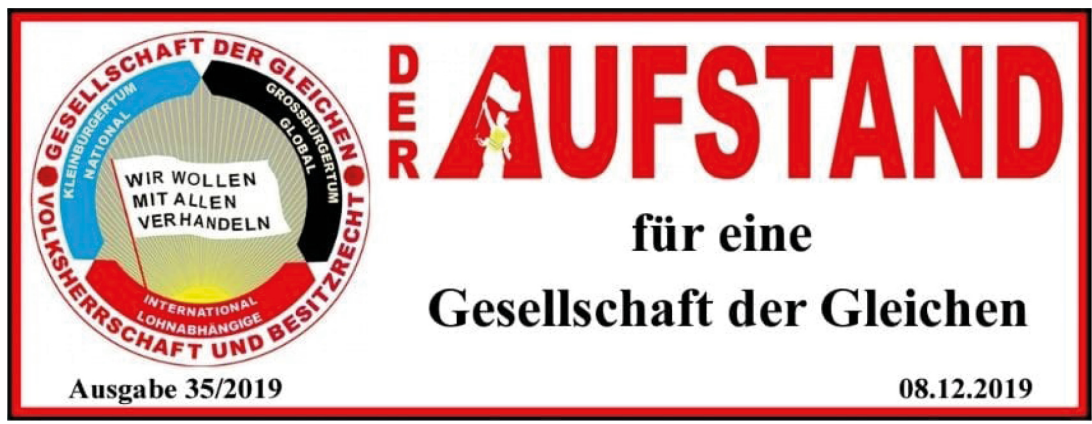

Для языка сообществ протестной мобилизации СС характерно использование вопросительных и восклицательных предложений, риторических вопросов, метафор, междометий. Все это связано с 
необходимостью завуалировать публикуемую информацию для достижения необходимой степени экспрессивности:

Braucht es noch Argumente, um am Sonntag Respekt und Vielfalt zu wählen und auch andere davon zu überzeugen? [BgRM]

Вам все еше нужны аргументы, чтобы проголосовать за уважение и многообразие в это воскресенье, а также убедить других это сделать?

Keine Zusammenarbeit mit der extremen Rechten! [BgRM]

Никакого сотрудничества с крайне правыми!

Чаще всего распространены так называемые «проективные интенции», направленные против методов работы или целей правящей верхушки:

all jene, die sich kritisch äußern, in eine rechte Ecke gestellt werden. Wer aber mit rechten Narrativen von fehlender Meinungsfreiheit und totalitärer Corona-Politik spielt, muss genau damit rechnen." [BgRM]

Все, кто высказывается критически, попадает в правый угол. Но всякий, кто играет с правыми нарративами об отсутствии свободы слова и тоталитарной короно - политикой, должен с этим считаться.

„Es geht nicht ums Schummeln. Es geht um bandenmäßigen Betrug "[DU]

Дело не в обмане! Речь идет о бандитском мошенничестве.

Kann es sein, dass ihr keine Ahnung habt, wie viele Menschen schon heute ständig ums Überleben kämpfen müssen?[FgA]

Возможно, вы даже не имеете понятия, сколько людей уже сегодня должны бороться постоянно за выживание?

Использование такого типа метафор воздействует на читателей за счет реализации аффективных оценочных оборотов, что способствует формированию у администратора или модератора положительного образа борца за права [5].

Вышеописанные жанровые характеристики сообществ социальных сетей позволили нам выделить следующие основные жанры CC: 
2021, Volume 13, Number 3 • http://soc-journal.ru

\begin{tabular}{|c|c|c|}
\hline Вид жанра & Описание & Пример \\
\hline Личный пост & $\begin{array}{l}\text { Разговорный стиль изложения с це- } \\
\text { лью заинтересовать адресанта. Для } \\
\text { интереса читателей используются } \\
\text { риторические вопросы, мемы, кар- } \\
\text { тинки, фото. Наличие функции ком- } \\
\text { ментирования, которую пользова- } \\
\text { тель при желании может отключить. }\end{array}$ & 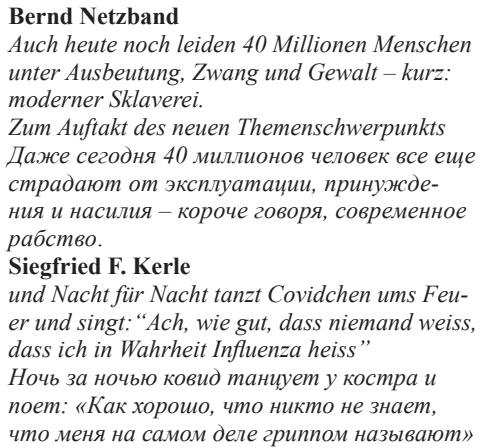 \\
\hline $\begin{array}{l}\text { Публичный } \\
\text { пост }\end{array}$ & $\begin{array}{l}\text { Запись, опубликованная на странице } \\
\text { сообщества после рассмотрения ее } \\
\text { модераторами. Может носить раз- } \\
\text { влекательный, познавательный, ин- } \\
\text { формационный или публицистиче- } \\
\text { ский характер. Является мультиме- } \\
\text { дийным или текстовым контентом. }\end{array}$ & $\begin{array}{l}\text { In der industriellen Massentierhaltung kommen } \\
\text { regelmäßig Antibiotika zum Einsatz. Der } \\
\text { massive Einsatz vor allem der sogenannten Re- } \\
\text { serveantibiotika stellt ein großes Gesundheits- } \\
\text { risiko dar - für die Tiere, aber erst recht für uns } \\
\text { Menschen. } \\
\text { Die Notmedikamente, in der Humanmedizin } \\
\text { als letzte Möglichkeit gegen resistente Bakteri- } \\
\text { en eingesetzt, werden in der Tierhaltung immer } \\
\text { häufiger verabreicht. Bilden die Tiere Resisten- } \\
\text { zen, können diese über den Fleischkonsum an } \\
\text { uns Menschen weitergegeben werden. } \\
\text { Еin neues Rechtsgutachten der Ärzteinitiative } \\
\text { „Ӓrzte gegen Massentierhaltung“ bestätigt, dass } \\
\text { die Rechtsgrundlagen in Deutschlandgegeben } \\
\text { sind, den Еinsatz von Reserveantibiotika zu ver- } \\
\text { bieten. } \\
\text { Unsere Аgrareхреrtin Reinhild Веnning рlädiert } \\
\text { daher dringend für einen neuen Gesetzesentwurf } \\
\text { Антибиотики регулярно используются в } \\
\text { промышленном животноводстве. В частно- } \\
\text { сти, массовое использование так называе- } \\
\text { мых резервных антибиотиков представляет } \\
\text { серьезную опасность для здоровья живот- } \\
\text { ных и, особенно для нас - людей. Лекар- } \\
\text { ства неотложной помощи, используемые в } \\
\text { медицине как последнее средство против } \\
\text { резистентных бактерий, все чаще применя- } \\
\text { ются в животноводстве. Если у животных } \\
\text { разовьется резистентность, это может быть } \\
\text { передано нам, людям, через потребление } \\
\text { мяса. } \\
\text { Новое юридическое заключение по ини- } \\
\text { циативе «Врачей против животноводства» } \\
\text { подтверждает, что в Германии существуют } \\
\text { законные основания для запрета использова- } \\
\text { ния резервных антибиотиков. Поэтому наш } \\
\text { эксперт Райнхильд Беннинг настоятельно } \\
\text { призывает к разработке нового законопро- } \\
\text { екта [DU]. }\end{array}$ \\
\hline
\end{tabular}




\begin{tabular}{|c|c|c|}
\hline Обсуждение & $\begin{array}{l}\text { Участие в тематических обсуж- } \\
\text { дениях. Наличие равноправных } \\
\text { участников с одинаковыми спосо- } \\
\text { бами взаимодействия. Отсутствие } \\
\text { строгого контроля со стороны моде- } \\
\text { раторов. Все пользователи группы } \\
\text { могут оставлять свои сообщения } \\
\text { под постом. }\end{array}$ & $\begin{array}{l}\text { Heute ein Jahr nach der rassistischen Gewalttat } \\
\text { in \#Hanau sind wir aufgerufen zu gedenken und } \\
\text { die Initiative 19. Februar Hanau in ihren Anlie- } \\
\text { gen um zu unterstützen. } \\
\text { Bernd Netzband } \\
\text { \#An diesem Tag Heute vor } 27 \text { Jahren, jag- } \\
\text { ten } 50 \text {-60 bewaffnete Neonazis stundenlang } \\
\text { Migrant*innen durch die Magdeburger Innen- } \\
\text { stadt und prügelten auf sie ein. Wir erinnern } \\
\text { heute insbesondere an die migrantischen Per- } \\
\text { spektiven auf den Tag... } \\
\text { В этот день, } 27 \text { лет назад, 50-60 вооружен- } \\
\text { ньх неонацистов часами преследовали ми- } \\
\text { грантов в иентре Магдебурга и избивали их. } \\
\text { Сегодня мь особенно напоминаем о взглядах } \\
\text { мигрантов на те события... }\end{array}$ \\
\hline Комментарий & $\begin{array}{l}\text { Самый распространенный и показа- } \\
\text { тельный жанр в социальных сетях. } \\
\text { Для него характерна быстротеч- } \\
\text { ность, комментирование определен- } \\
\text { ной заметки длится от } 1 \text { до } 3 \text { дней. } \\
\text { Короткий объем комментария при- } \\
\text { водит к лаконичности выражаемой } \\
\text { мысли, использованию всевозмож- } \\
\text { ных аудио- и видеосредств, особой } \\
\text { раскладки клавиатуры с целью при- } \\
\text { влечения внимания. }\end{array}$ & 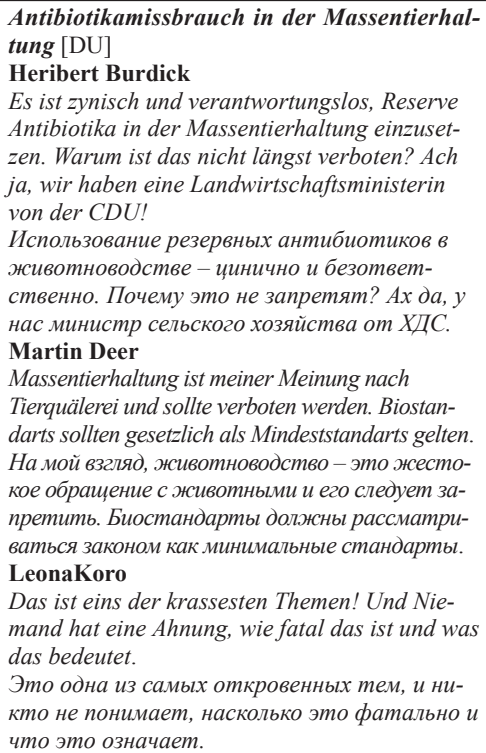 \\
\hline
\end{tabular}

Проведенный нами анализ показал, что не все функции и параметры, типичные для интернет-коммуникации нашли свое отражение в сообществах протестной коммуникации в социальных сетях. Так, нами не было зафиксировано употребление оригинальных сложных слов, распространенных морфем, жаргонизмов и т.д. В отличие от блогов, где в качестве инструмента манипуляции активно используются т.н. «пластиковые слова», в сообществах социальных сетей они практически не встречаются. «Пластиковые слова»- термины, заим- 
ствованные в другой сфере использования, возврат которых к предыдущей сфере использования ведет к определенному семантическому опустошению. Так, пластиковое слово Kommunikation очень быстро вытеснило такие лексические единицы, как Gespräch, Unterhaltung или Plausch. Information встречается сегодня в речи политиков во всевозможных комбинациях: Informationsflut, Informationszeitalter, Informationsaustausch. Эти факторы можно объяснить простотой разговорной бытовой речи, используемой участниками сообществ.

\section{Выводы}

Жанровая и дискурсивная специфика протестной коммуникации в сообществах СС характеризуется высокой гибридностью вследствие гетерогенного характера изучаемого объекта. Процесс мобилизации считается релевантным и может быть реализован при помощи внутреннего и внешнего механизмов, субъектов коммуникации и отношений между ними. Анализ статистики сообществ показал, что формат сообщества и его состав взаимозависимы с показателями информирования, управления и мобилизации; размещение постов не обусловлено параметрами и величиной сообщества; для больших и малых сообществ характерны разные формы онлайн-участия; доля активного участия в коммуникации не определяется величиной сообщества. Все рассмотренные сообщества имеют схожий интерактивный инструментарий.

Содержательное наполнение информационного ресурса сообществ конфликтной мобилизации в СС включает в себя следующие типы публикаций: модерируемые публикации с открытой мобилизацией членов группы в участии конкретного протестного онлайн/ офлайн-мероприятия; информационные публикации участников сообщества с целью сплочения против чего-либо; сторонние публикации, ссылками на которые делятся члены сообщества.

Дискурсивная комбинированность и визуализированность сообществ СС заключается в информационном, политическом, публицистическом, социально-ориентированном, интернет-дискурсе, общими показателями которых являются массовый адресат, аргументированность, фактичность, демонстрация собственной позиции. 
Специфика жанрового наполнения определяется совокупностью прагматических, медийных, стилистических, структурных параметров, корреляцией между предметом выступления и интерпретацией изложенных фактов.

Исследование выполнено при финансовой поддержке РФФИ в рамках научного проекта № 20-012-00193«Протестная коммуникация в современном информационном пространстве России и Германии» [The reported study was funded by RFBR, project number 20-012-00193].

\section{Список литературы}

1. Александрова О.В. Соотношение устной и письменной речи и язык СМИ // Язык средств массовой информации / Под ред. М. Н. Володиной. М.: Академический проект; Альма Матер, 2008. С. 337-348.

2. Баженова Е.А., Иванова И.А. Блог как интернет-жанр // Вестник Пермского университета. 2012. № 4 (20). С. 121-131. http://www.rfp. psu.ru/archive/4.2012/bazhenova.pdf

3. Бараш Р.Э., Антоновский А.Ю. Современная протестная коммуникация в контексте системно-коммуникативного подхода // Коммуникации. Медиа. Дизайн. 2019. № 4 (3). С. 140-164. https://cmd-journal. hse.ru/article/view/10189/11037

4. Вербилович О. Теория коммуникативного действия: ключевые категории и познавательный потенциал // Публичная сфера: теория, методология, кейс-стадии. М.: ООО «Вариант» ЦСПГИ, 2013. С. 35-52.

5. Генералова Л.М. Жанровая специфика политического блога // Мир науки, культуры, образования. 2020. № 3 (82). С. 500-503.

6. Гончаров Д.В. Политическая мобилизация // Полис. Политические исследования. 1995. № 6. С. 129-137.

7. Дейк ван Т.А. Язык, познание, коммуникация. Благовещенск: БГК им. И.А. Бодуэна де Куртенэ, 2000. 308 с.

8. Докука С.В. Коммуникация в социальных онлайн-сетях как фактор протестной мобилизации в России: Автореф. дис. ... канд. социол. наук: 22.00.04. М., 2014. 27 с. 
9. Есиев Э.Т. Технологии сетевой конфликтной мобилизации: формы и задачи // Русская политология - Russian Political Science. 2017. № 2. С. 34-41.

10.Карпоян C.M. Instagram как особый жанр виртуальной коммуникации // Филологические науки. Вопросы теории и практики. Тамбов: Грамота, 2015. № 12(54): в 4-х ч. Ч. III. C. 84-88. https://www. gramota.net/materials/2/2015/12-3/21.html

11. Киняшева Ю.Б. Социальные сети как инструмент политической мобилизации граждан в современной России // Известия Тульского государственного университета. Гуманитарные науки. 2018. № 3. С. 3-10.

12. Кондрашов П.Е. Компьютерный дискурс: социолингвистический аспект: Автореф. дис. ... канд. фил. наук: 10.02.19. Краснодар, 2004. 19 с.

13. Курочкин А.В., Шерстобитов А.С. Роль социальных сетей в становлении нового пространства коммуникаций современной России // Проблемы современной науки и образования. 2016. № 35 (77). С. 111-115.

14. Осипов В. Из замкнутого круга выживания. http://www.soob. $\mathrm{ru} / \mathrm{n} / 2003 / 1 /$ practice/37/ (дата обращения: 5.06. 2021)

15. Шерстобитов А.С., Брянов К.А. Технологии политической мобилизации в социальной сети «В Контакте»: сетевой анализ протестного и провластного сегментов // Исторические, философские, политические и юридические науки, культурология и искусствоведение. Вопросы теории и практики. Тамбов: Грамота, 2013. № 10(36). В 2-х ч. Ч. I. C. 196-202. https://www.gramota.net/materials/3/2013/10-1/52.html

16. Щипицина Л.Ю. Жанры компьютерно-опосредованной коммуникации: Монография. Архангельск: Поморский ун-т, 2009. 236 с.

17. Яницкий О.Н. Массовая мобилизация: проблемы теории // СОЦИС: социологические исследования. 2012. № 6. С. 3-12. https://www. isras.ru/files/File/Socis/2012_6/Yanitskiy.pdf

18. Habermas J. The theory of communicative action. Boston: Beacon Press, 1987. V. 2. 328 p.

19. Milan S. From social movements to cloud protesting: the evolution of collective identity // Information, Communication \& Society. 2015. Vol. 18, № 8, pp. 887-900. https://doi.org/10.1080/1369118X.2015.1043135 20.Pörksen U. Plastikwörter. Die Sprache einer internationalen Diktatur. Stuttgart: Klett-Cotta, 2011, $128 \mathrm{~S}$. 
21. Siegel D.A. Social networks and collective action // American Journal of Political Science.2009. Vol. 53(1), pp. 122-138. https://www.jstor.org/ stable/25193871

\section{References}

1. Aleksandrova O.V. Sootnoshenie ustnoi i pis'mennoi rechi i yazyk SMI [Speech / writing ratio and media language]. Yazyk sredstv massovoi informasii [Language of the mass media]. Moscow: Akademicheskii proekt; Alma mater, 2008, pp. 337-348.

2. Bazhenova E.A., Ivanova I.A. Blog kak internet-zhanr [Blog as an Internet genre]. Vestnik Permskogo universiteta [The Perm University Bulletin], 2012, no. 4 (20), pp. 121 -131. http://www.rfp.psu.ru/archive/4.2012/bazhenova.pdf

3. Barash R.E., Antonovskiy A.Yu. Sovremennaya protestnaya kommunikatsiya $\mathrm{v}$ kontekste sistemno-kommunikativnogo podhoda [Modern protest communication in the context of a systemic-communicative approach]. Kommunikatsii. Media. Dizain [Communications. Media. Design], 2019, no. 4 (3), pp. 140-164. https://cmd-journal.hse.ru/article/view/10189/11037

4. Verbilovich O. Teoriya kommunikativnogo dejstviya: klyuchevye kategorii i poznavatelnyj potencial Theory of communicative action: key categories and cognitive potential]. Publichnaya sfera: teoriya, metodologiya, kejs-stadii [Public sphere: theory, methodology, case stages]. Moscow: OOO "Variant" TsSPGI, 2013, pp. 35-52.

5. Generalova L.M. Zhanrovaya specifika politicheskogo bloga [Genre specificity of the political blog]. Mir nauki, kultury, obrazovaniya [The world of science, culture, education], 2020, no. 3 (82), pp. 500-503.

6. Goncharov D.V. Politicheskaya mobilizatiya [Political mobilization]. Polis. Politicheskie issledovaniya [Polis. Political studies], 1995, no. 6, pp. 129-137.

7. Dejk van T.A. Yazyk, poznanie, kommunikaciya [Language, cognition, communication]. Blagoveshhensk: BGK im. I. A. Bodujena de Kurtenje, 2000, $301 \mathrm{p}$.

8. Dokuka S.V. Kommunikatsiya v social'nychonlain-setyachkak factor protestnoi mobilizatii v Rossii [Communication in social online networks 
as a factor of protest mobilization in Russia]: Abstract of $\mathrm{PhD}$ dissertation: 22.00.04. Moscow, 2014, 27 p.

9. Esiev Je.T. Technologii setevoj konfliktnoj mobilizatii: formj i zadachi [Technologies of network conflict mobilization: forms and tasks]. Russkaya politologiya [Russian political science], 2017, no. 2, pp. 34-41.

10. Karpoyan S.M. Instagram kak osobyj zhanr virtual'noj kommunikacii [Instagram as a special genre of virtual communication]. Filologicheskie nauki. Voprosj teorii i praktiki [Philological sciences. Theory and practice]. Tambov: Gramota, 2015, no. 12(54), part III, pp. 84-88. https:// www.gramota.net/materials/2/2015/12-3/21.html

11. Kinyacheva Yu.B. Socialnye seti kak instrument politicheskoi mobilizatii grazhdan v sovremennoi Rossii [Social networks as an instrument of political mobilization of citizens in modern Russia]. Izvestiya Tulskogo gosudarstvennogo universiteta. Gumanitarnye nauki [The Tula State University Bulletin. Humanitarian sciences], 2018, no. 3, pp. 3-10.

12. Kondrashov P.E. Komp'yuternyi diskurs: sociolingvisticheskii aspect [Computer discourse: sociolinguistic aspect]: Abstract of $\mathrm{PhD}$ dissertation: 10.02.19. Krasnodar, 2004, 19 p.

13. Kurochkin A.V., Sherstobitov A.S. Rol'sozialnych setei v stanovlenii novogo prostranstva sovremennoi Rossii [The role of social networks in the formation of a new space of communications in modern Russia]. Problemy sovremennoi nauki i obrazovaniya [Problems of modern science and education], 2016, no. 35 (77), pp. 111-115.

14. Osipov V. Iz zamknutogo kruga vyzhivaniya [Out of the vicious circle of survival]. http://www.soob.ru/n/2003/1/practice/37/ (accessed 5.06. 2021).

15. Sherstobitov A.S., Bryanov K.A. Technologii politicheskoi mobilizatii v sozial'noi seti "V kontakte": setevoi analiz protestnogo i provlastnogo segmentov [Technologies of political mobilization in the VKontakte social network: network analysis of the protest and pro-government segments]. Istoricheskie, filosofskie, politicheskie i yuridicheskie nauki, kulturologiya i iskusstvovedenie. Voprosy teori i i praktiki [Historical, philosophical, political and legal sciences, cultural studies and study of art. Theory and practice]. Tambov: Gramota, 2013, no. 10(36), part I, pp. 196-202. https://www.gramota.net/materials/3/2013/10-1/52.html 
16. Shipicyna L.Yu. Zhanry kompyuterno-oposredovannoi kommunikacii: Monografiya [Genres of computer-mediated communication: Monograph]. Archangel'sk: Pomorskii universitet, 2009, 236 p.

17. Yanickii O.N. Massovaya mobilizaciya: problem teorii [Mass mobilization: problems of theory]. SOCIS: sociologicheskie issledovaniya [SOCIS: sociological research], 2012, no. 6, pp. 3-12. https://www.isras.ru/ files/File/Socis/2012_6/Yanitskiy.pdf

18. Habermas J. The theory of communicative action. Boston: Beacon Press, 1987, vol. 2, 328 p.

19. Milan S. From social movements to cloud protesting: the evolution of collective identity. Information, Communication \& Society, 2015, vol. 18, no. 8, pp. 887-900. https://doi.org/10.1080/136911 8X.2015.1043135

20. Pörksen U. Plastikwörter. Die Sprache einer internationalen Diktatur. Stuttgart: Klett-Cotta, 2011, 128 S.

21. Siegel D.A. Social networks and collective action. American Journal of Political Science, 2009, vol. 53, no. 1, pp. 122-138. https:/www.jstor. org/stable/25193871

\section{ДАННЫЕ ОБ АВТОРЕ}

Генералова Лариса Михайловна, кандидат филологических наук, доцент кафедры германской и романской филологии Волгоградский государственный университет пр-т Университетский, 100, г. Волгоград, 400062, Российская Федераичя l.m.generalowa@volsu.ru

\section{DATA ABOUT THE AUTHOR}

Larisa M. Generalova, $\mathrm{PhD}$ in Philology, Associate Professor Volgograd State University 100, Universitetsky Ave., Volgograd, 400062, Russian Federation l.m.generalowa@volsu.ru SPIN-code: 6028-6456

ORCID: 0000-0003-0807-391X 